\title{
Robotic and Mechanotherapeutic Technology to Restore the Functions of the Upper Limbs: Prospects tor Development (Review)
}

\author{
DOI: 10.17691/stm2016.8.4.27
}

Received April 6, 2016

L.A. Chernikova, MD, DSc, Professor, Chief Researcher, Neuro-Rehabilitation Department';

N.A. Suponeva, MD, PhD, Neurologist, Neurophysiologist, Head of the Neuro-Rehabilitation Department';

A.S. Klochkov, MD, PhD, Senior Researcher, Neuro-Rehabilitation Department';

A.E. Khizhnikova, PhD Student, Neurologist, Neuro-Rehabilitation Department';

R.H. Ly ukmanov, Junior Researcher, Neuro-Rehabilitation Department';

E.V. Gnedoyskaya, MD, PhD, Deputy Director for Scientific and Organizational Work and Development';

D.S. Yankevich, MD, PhD, Deputy Director of the Department for Coordination and Maintenance of Organizational Activities in the Field of Medical Sciences, Healthcare, Education and Culture²; M.A. Piradov, MD, DSc, Professor, Academician of the Russian Academy of Sciences, Director ${ }^{1}$

${ }^{1}$ Research Centre of Neurology, 80 Volokolamskoye Shosse, Moscow, 125367, Russian Federation; ${ }^{2}$ Federal Agency for the Scientific Organizations of Russia, 32a Leninsky prospect, Moscow, 119334, Russian Federation

We have analyzed the advantages and disadvantages of the robotic and mechanotherapeutic technologies used for rehabilitation of the upper limbs. Robotic and mechanotherapeutic devices started as simple controllers and upper limb weight support systems in kinesitherapy, but have subsequently shown their potential as systems for providing task oriented movement training, by efforts to maximize the correspondence between the features of anatomical and biomechanical arms. Integration of functional neuromuscular electrostimulation with robotic and mechanotherapeutic technology considerably widens the possibilities of using robots for rehabilitation and for providing mechanical assistance, while the appearance of portable and fixed exoskeletons is leading to completely new devices based on both rehabilitation and assistive technologies. Currently prototypes of robotic assistive and rehabilitation devices controlled by brain-computer interfaces are being developed.

Key words: robotic technology; rehabilitation after stroke; exoskeleton; brain-computer interface; mechanotherapy.

Introduction. Strokes are the leading cause of disability throughout the world, and are especially significant in Russia [1-4]. According to many authors [5-9], only one in five patients completely recovers all movement of their upper limbs after a stroke. Poor recovery is often the result, not only of the sizes and localization of the poststroke foci, but of such diseases as diabetes mellitus, arterial hypertension, cardiovascular insufficiency, deep vein thrombosis of the legs, osteoporosis and epilepsy, and this considerably complicates the course of recovery and impairs the outcomes [10-13]. These factors present a difficult background that it is hard to modify in the acute and subsequent periods, however, there is also a second group of factors involved in limiting the effectiveness of rehabilitation and these can be partially corrected. First and foremost of these is the patients' low motivation for training, and a tendency toward depression, apathy and negative views of their own rehabilitation potential, as well as, at a later stage, the occurrence of secondary complications such as arthropathy of the shoulder joint and muscle contractures [14-17]. At an early stage after the stroke, when recovery of the lost function could have the greatest impact, these problems can lead to reduced effectiveness of rehabilitation and are often the reason for its limited success. It is the intensity of rehabilitation, and an early and comprehensive approach to the recovery of lost functions that are indispensable for a successful rehabilitation process [18-25]. Modern approaches to motor training are based either on the concept of taskoriented approaches. These, unlike traditional approaches aimed at the restoration of individual movements and functions, are oriented at training and restoration of the specific motions involved in completing tasks [26-30]. The upper limb of a human is considered the most developed and effective manipulative organ, comprised, as it is, of a complex kinematic chain consisting of the shoulder, elbow and wrist joints as well as the hand joints. The most mobile joint in the whole human body is the shoulder joint,

For contacts: Natalia A. Suponeva, e-mail: nasu2709@mail.ru 
having three degrees of freedom that allow it to move in three planes and with respect to the three main axes. In addition to enabling self-care of the body, the mobility of the shoulder joint also has the function of providing for object-reaching, allowing people to reach objects at distance in addition to maintaining the most convenient position for the proximal part of the upper limb to grip the object [31, 32]. The elbow joint, being the most complex combined joint, helps realize the flexion/extension and pronation/supination that enable the forearm to place the hand at the required distance from the body. Flexion of the elbow joint is important in enabling a person to bring food to their mouth. The wrist joint is the distal joint of the upper limb that enables the hand, as an executive segment, to take up an optimal position for performing gripping functions.

The human upper limb is thus a versatile tool, able to perform a large number of functions due to its most important action of gripping and the ability to take up an optimal position for any specific action. This ability is the result, mainly, of the large number of degrees of freedom in the upper arm joints [33].

Rehabilitation exercises used by physical therapists have always included the use of different devices to facilitate different tasks. However, the frequent repetition of just one exercise is difficult, especially if there is a need for physical force provided by the instructor or for the use of body-weight support systems. Previously, an effective solution has been to construct a range of devices combining the ability to create the conditions required, not only for successful rehabilitation, but also for adaptation of the upper limb to its state of paresis.

For complex hardware rehabilitation of the upper limbs a wide range of robotic and mechanotherapeutic devices is currently in use [34-38]. These devices can be considered in two main categories: robotic and mechanotherapeutic. The robotic ones are those devices equipped with motors to perform or assist in the required movement, they are anthropomorphic (having similar working principles to the corresponding biological component) and interactive (with the ability to change the stereotype of their work depending on the environmental conditions or the patient's particular activity). Unlike robotic devices, mechanotherapeutic ones have actuators to perform only a set of programmed movements. Both types can be equipped with sensors and therefore make use of biological feedback [39-41].

The objective of this review is to analyze the advantages and disadvantages of the robotic and mechanotherapeutic technologies used in the rehabilitation of upper limb function in patients following strokes, and to determine their possibilities for innovative development in the field of medical rehabilitation.

The first rehabilitation robot was MIT-Manus, a robotmanipulator developed the 1990s at the Massachusets Institute of Technology (USA). It helped in retraining of the shoulder and elbow joints but had two degrees of freedom only in the horizontal plane and the patient's hand mounted on the MIT-Manus joystick [42-45]. In due course, this robot was equipped with a vertical module with antigravity support that helped train the paretic upper limb in not only the horizontal, but also the vertical plane. Subsequently the system was equipped with a module with three degrees of freedom, providing training of the hand [46].

In 2007 an enhanced MIT-Manus model was developed that trained the wrist, elbow and shoulder, having five degrees of freedom in total [47, 48].

Another robot aimed at training movements in the shoulder and elbow joints was the Mirror Image Movement Enabler (MIME), developed at Stanford University (USA) $[49,50]$. This robot allowed training in passive, active-assisting, active-coercion and bimanual modes. In the passive mode the patient relaxes as the robot performs the required arm movement to the target using a predetermined trajectory. In active-assisting mode the patient voluntarily initiates the movement to the target and then the robot helps to perform the action. In an active-coercion mode the robot provides a certain amount of resistance in the direction of movement, requiring the patient to overcome this. In bimanual mode the patient performs the movement with both arms, with the robot assisting the paretic limb by mirroring the movement of the healthy one $[51,52]$.

At the beginning of the 2000s a team of researchers from Berlin [53, 54] developed a robot, the Bi-ManuTrack for bimanual training of the upper limbs. Unlike the previous device it did not assist in shoulder movements, but was targeted at the one-sided and two-sided training of pronation/supination of the forearm, and at flexion/ extension of the hand. A number of studies confirmed the effectiveness of this robot in respect of its assistance to patients with post-stroke hemiparesis [55, 56], and to patients suffering from Parkinson's disease [57].

In 2006 a group of Italian scientists [58-60] presented a new robot-manipulator, the NeReBot, that helped patients make movements in the proximal part of the upper limb (flexion/extension, pronation/supination, adduction/abduction, as well as circular movements at the shoulder and elbow) both in the sitting position and in the supine position, resulting in a widened range of application possibilities $[61,62]$.

A robot-manipulator, the HapticMaster, created in the Netherlands in 2006, allowed training in pronation/ supination in the forearm and in flexion/extension of the hand. It was applied to the training of movements in patients with multiple sclerosis, and study [63] investigated, particularly, the effect of weight support of the arm being trained, on the effectiveness of robot therapy. Analysis of the findings indicated a significant increase in the range of active movements in the joints of the upper arm, after a course of training with the system set for antigravity support, that was not observed in the patients from the control group.

The use of robot-therapy in clinical practice has shown that motor training for targeted movements requires that 
the devices used are matched to the anatomical and biomechanical characteristics of the upper limbs. This is necessary to provide for full control over the movements in each joint, especially when performing a complex movement, in order to ensure effectiveness and safety during the training [64-69].

The most obvious and effective development need was, of course, to create mechanotherapeutic devices having an exoskeleton construction.

The age of rehabilitation exoskeletons of the upper limbs started in the 2000s with the creation of the Assisted Rehabilitation and Measurement (ARM) Guide, and the Therapy Wilmington Robotic Exoskeleton (T-WREX). These devices are exoskeletons (i.e. external frames) for the upper limb that unload its weight and transmit feedback onto a monitoring screen, allowing evaluation and training linked to the movement trajectory. Among various current, actively-used technologies one system, the Armeo system (Hocoma, Switzerland) [70], based on the ARMIN exoskeleton, deserves special attention. A distinctive feature of the ArmeoSpring exoskeleton complex is the weight support of the arm with spring rods that allow training even of patients having a minimal range of active movements. All such training is conducted in a virtual environment under the control of biofeedback. Complex training exercises involve programs imitating daily household activities, therefore implementing task oriented approaches in the motor training.

Another evolutionary step in the development of rehabilitation devices for the upper limbs was the ArmeoPower complex. This was additionally equipped with electrical drives to provide upper limb unloading. As it offers interactive assistance in performing the exercises, this places it in the robotic devices category [71]. The use of electrical drives opens up completely new opportunities for training patients with plegia and severe paresis. A kinesitherapy specialist can perform a passive movement, of any degree of complexity and length, with a patient's arm, and then the ArmeoPower can accurately repeat this movement as often as necessary, providing cyclic complex passive rehabilitation of the paretic limb joints. This offers an effective method for treating and preventing contractures.

Other examples of the use of enhanced rehabilitation technology are provided by devices offering integrated functional electrical stimulation. Normal, and even functional, neuromuscular electrical stimulation, has been applied in rehabilitation therapy for a long time [72], but in recent years it has become possible to integrate this with the robotic and mechanotherapeutic technologies [73, 74]. Today there are still no complete exoskeleton systems for the upper limbs with a built-in interactive system of functional electrical stimulation, but such prototypes are being actively worked on, so it can be expected that they will appear in the very near future. The effectiveness of using functional electrical stimulation has been proved, so it is reasonable to include this technology into modern rehabilitation devices.
In the last two years, electromyographic sensors have been actively used to manage both exoskeletons and robots. We already have prototypes of devices based on the registration of electromyographic signals from the upper limb. In $2014 \mathrm{Li}$ et al. [75] developed a protocol for the registration and analysis of electromyographic data to control a prototype robotic exoskeleton of the upper limbs. In 2015 Cesqui et al. used myography to manage a MITManus robot for the rehabilitation of patients after strokes [76]. In the same year Tong, Hu et al. used a myographycontrolled exoskeleton for the wrist $[77,78]$.

A particular challenge during the motor rehabilitation of the upper limb is the recovery of fine motor skills of the hand. A phylogenetically shaped hand needs to perform static, dynamic and sensory functions. To grip an object a person forms a new 'mechanism' with the hand, creating novel positions depending on the purpose of the movement and the character of the object (size, weight, shape, texture). The accuracy and strength of the grip is not only determined by all parts of the hand - fingers and wrist, but, importantly, also depends on the functioning of the shoulder girdle, shoulder, elbow and forearm. The gripping and holding of objects involves complex motor actions, which consist of a number of preparatory operations [79-82]. Some of the existing simulators are equipped with sensors in the handling device and a system of biological feedback to train the gripping action. However, for patients with high muscular tonus in the flexor digitorum and a lack of active extension, such training is impossible.

In 2009, for robotic training in the cylindrical gripping function, a rehabilitation robot-exoskeleton, the Hand Exoskeleton Rehabilitation Robot (HEXORR, USA), was developed. It was aimed at assisting with the use of all fingers and returning a full range of movements to them [83]. HEXORR can perform both passive and passiveactive training, when all the drives work in supplementary mode, evaluating with sensors the full range of assistance required to perform flexion or extension. Unfortunately, having only two drives: one for the thumb and the other for the rest of the fingers HEXORR cannot assist in more complicated interdigital grips. Furthermore, as it is only a hand exoskeleton, so training of complex hand movements in combination with arm straightening is not possible.

In 2010, and based on the Hand Spring Operated Movement Enhancer (HandSOME, USA), the ManovoSpring module was developed to train a gripping and relaxation function, involving passive finger extension $[84,85]$. Using it in association with the ArmeoSpring mechanotherapeutic complex helped patients to unbend their fingers after performing an active grip, by the use of a regulated spring rod. Due to the regulated force of finger extension the ManovoSpring allows active/passive training of the function of gripping/relaxation. Its special feature is the combination of mechanotherapeutic training of all the proximal parts of the upper limbs, which allows training in cylindrical gripping as an element of a complex hand movement: for example, to reach an object, 
grip it and to place it in a new location. The majority of simulators and robotic devices intended for training fine motor skills of the hand have the form of an exoskeleton equipped with electrical or pneumatic-drives for each finger. Mostly, these exoskeleton devices are made in the form of a glove which can be either flexible or rigid. So, the SCRIPT exoskeleton of the forearm and hand [86] is a passive orthesis which can assist movement with springs and elastic rods. The orthesis is equipped with goniometry sensors and potentiometers that can be used, not only for providing biological feedback, but also for evaluating the movements and dynamics of rehabilitation. The Gloreha Hand Rehabilitation Glove [87] is a soft exoskeleton, the distinguishing feature of which is its open palm surface, allowing tactile contact with objects during passive household exercises. One of the problems of using rigid glove-shaped exoskeletons is their weight: the patient needs to exert considerable force simply to hold the hand in the air when wearing one. The inventors of the Hand of Hope, five-finger hand exoskeleton, solved this problem with a support for the forearm, which can track the movements of the patient's hand in a horizontal plane. Another feature of this exoskeleton is its management using electromyography registered from the finger extensor and flexor muscles [88, 89].

It is noteworthy that not all robotic devices for training fine motor skills take the form of exoskeletons. Thus, for example, the Amadeo robotic system designed for active, passive and assistive training of hand function and fine motor skills [90], has five movable carriages to which the hand and the patient's fingers are attached with magnetic pads. An advantage of this construction is its versatility for patients with different palm sizes and for use with children. On the basis of the biological feedback implemented by the Amadeo programs in training proprioceptive sensitivity, training exercises for isolated movements in individual fingers have become possible, beyond those of abnormal motor synergy. To train the patients with severe paresis, Amadeo has the capability to manage the carriages by using myographic registration.

A completely different, somewhat complicated, yet high-priority task is the recovery of sensitivity. It is sensitivity impairment that sometimes prevents patients from using the paretic upper limb, even where their muscular strength has been sufficiently recovered. In 2011 a group of researchers from Switzerland developed a robotic simulator designed solely for helping in the recovery of sensitivity in distal parts of the upper limb and fingers. The Robotic Sensory Trainer uses vibrating drives under the fingertips, proximal phalanges and the proximal part of the palm, as well as force sensors located under each finger and the palm. The training is conducted under biological feedback, with the paretic upper limb hidden from the patient [91].

However, despite the wide spectrum of robotic devices and the considerably increased possibilities of modern rehabilitation, it is still not always possible to restore lost functions of the upper limb. The requirement of these patients for independent living has resulted in a completely new type of technology - assistive robots. Assistive robots are not intended to restore motor functions; their task is to provide assistance to the patient in achieving a required task. As a rule, these devices are used for daily household needs, assisting the patient in independently completing particular tasks. In cases where the range of active movements in the upper limb is considerably limited, robotic manipulators, controlled by the patient, can be used; they completely fulfill the actions required by the patient. In 1987, Topping developed the first robotic manipulator, Handy 1. It was aimed at facilitating the process of feeding in children who had cerebral palsy [92]. A manipulator created by the RAIL (Robotic Aid to Independent Living) project and controlled by the patients, helped them to eat, drink, brush their teeth and to shave. With developments in the technology, modern robotic manipulators have become more compact, versatile and more affordable, and this is important for consumers using them for individual goals. Among the manipulators currently being produced we should mention the Bestic (Sweden, 2004) which is a desk-top device for feeding patients. Controlled using buttons and a joystick, or a foot pedal, the Bestic can scoop liquid or solid food with a spoon from a given plate and bring the spoon to the patient's mouth. One of the main drawbacks of this kind of manipulator is its narrow specialization and dependence on the surrounding environment. This problem can be solved by using mobile "portable" multifunctional manipulators with three or more degrees of freedom. The existing models of this type of assistive manipulator enable the performance of practically all the main functions of the upper limb. Among a considerable number of devices, the iARM manipulator (Exact Dynamics, Holland) and its further variant, the JACO (Kinova, Canada, 2009), should be mentioned. These devices can be fixed, desk-top or portable and integrated into a wheelchair with an electrical drive. Management of this manipulator is performed manually, if necessary by the patient's mouth, using a joystick. Currently a prototype robotic manipulator controlled by a brain-computer interface is being developed. When the EEG signals are accurate, these devices can offer more precise and rapid management than by those from the patient's arm. However, to substitute the impaired limb with a manipulator is not always necessary. When there are minimal voluntary movements it is enough to unload the arm weight, creating the effect of weightlessness, enabling the patient to use the impaired limb to its fullest extent. A device of this type is the Edero (Armon, Holland) dynamic weight support system. This system, equipped with a spring for arm weight support, can be mounted on the patient's chair where it helps in the performance of daily household tasks: eating, drinking, combing the hair, lifting objects etc.

Another aspect of using brain-computer interface technology is in the rehabilitation of motor functions. Noninvasive registration of sensor-motor EEG rhythms is 
most frequently used as a background for showing realtime feedback for mentally performed motor exercises. Of the different feedback modalities, the kinesthetic one is being studied at the moment. It is manifested by a hand exoskeleton which implements the imagined movement. Neurophysiological studies have shown the impact of this approach on activation of the processes of neuroplasty, and clinical data confirm its effectiveness on rehabilitation in patients following a stroke [93-95].

The Magnitogorsk Scientific Development and Production Center "Android Technics" under the supervision of the Russian N.I. Pirogov National Research Medical University has developed a multiaxial exoskeleton of the upper limb with seven degrees of freedom and a hand module able to work with a noninvasive braincomputer interface for training in complex functionally important movements.

It should be stressed that this technology combines two methods: robot therapy and mental training, and that the effectiveness of each has been proved for post-stroke paresis of the upper limbs [96, 97].

Thus, practical experience of using robotic and mechanical therapy enables us to specify some of the requirements for, and to make recommendations regarding high-tech motor rehabilitation: the help provided by robotic devices should be minimally sufficient; the patient's own level of motivation should be stimulated; the range of training programs and the use of biological feedback needs to be better consolidated; monotherapy is to be avoided, motor functions should be regularly evaluated and the extent of unloading adjusted accordingly. Existing robotic technologies allow the most effective kinesitherapy for practically all isolated and complex arm movements, including targeted ones. Development of the technology and expansion of the range of these devices to make them more compact and more affordable will enable patients to continue courses of active complex rehabilitation at home, facilitating further recovery.

Robotic and mechanical therapy devices designed for training impaired functions of the upper limb are being actively developed and studied abroad. These developments are based on the main principles of modern training theory and on the latest achievements in the field of understanding neuroplastic processes in the CNS. Robot therapy is one of the main rehabilitation technologies, the effectiveness of which is confirmed by evidence-based medicine. At the same time the high price of these devices is one of the main constraints on their wide-spread implementation in public healthcare. In Russia there have been individual attempts to create robot-exoskeletons, for example, the Neurobotix, (Magnitogorsk Scientific Development and Production Center "Android Technics"), and this is currently undergo clinical trials.

Conclusion. The combination of modern mechanotronic, electronic and computer technologies is contributing to the developments in this direction and to the creation of new exoskeletons/robots that can increase the effectiveness of recovery of lost motor functions of the upper limbs.

Study Funding. The study was performed under State Scientific Research (Project No.115013010106).

Conflicts of Interest. The authors declare no conflicts of interest.

\section{References}

1. Piradov M.A. Stroke intensive care: voice a view. Annaly klinicheskoy i eksperimental'noy nevrologii 2007; 1(1): 17-22.

2. Piradov M.A., Suslina Z.A., Tanashyan M.M. Printsipy lecheniya ostrykh ishemicheskikh narusheniy mozgovogo krovoobrashcheniya. V kn.: Ocherki angionevrologii [Principles of treating acute ischemic disorders of cerebral circulations. In: Angoineurology assays]. Moscow; 2005; p. 206-215.

3. Truelsen T., Piechowski-Jozwiak B., Bonita R., Mathers C., Bogousslavsky J., Boysen G. Stroke incidence and prevalence in Europe: a review of available data. Eur $J$ Neurol 2006; 13(6): 581-598, https://doi.org/10.1111/j.14681331.2006.01138.x.

4. Winstein C.J., Stein J., Arena R., Bates B., Cherney L.R., Cramer S.C., Deruyter F., Eng J.J., Fisher B., Harvey R.L., Lang C.E., MacKay-Lyons M., Ottenbacher K.J., Pugh S., Reeves M.J., Richards L.G., Stiers W., Zorowitz R.D.; American Heart Association Stroke Council, Council on Cardiovascular and Stroke Nursing, Council on Clinical Cardiology, and Council on Quality of Care and Outcomes Research. Guidelines for adult stroke rehabilitation and recovery: a guideline for healthcare professionals from the American Heart Association/American Stroke Association. Stroke 2016; 47(6): e198-e169, https://doi.org/10.1161/ STR.0000000000000098.

5. Beebe J.A., Lang C.E. Active range of motion predicts upper extremity function 3 months after stroke. Stroke 2009; 40(5): 1772-1779, https://doi.org/10.1161/ strokeaha.108.536763.

6. Simpson L.A., Eng J.J. Functional recovery following stroke: capturing changes in upper-extremity function. Neurorehabil Neural Repair 2012; 27(3): 240-250, https://doi. org/10.1177/1545968312461719.

7. Lum P.S., Godfrey S.B., Brokaw E.B., Holley R.J., Nichols D. Robotic approaches for rehabilitation of hand function after stroke. Am J Phys Med Rehabil 2012; 91: S242S254, https://doi.org/10.1097/phm.0b013e31826bcedb.

8. Parker V.M., Wade D.T., Hewer R.L. Loss of arm function after stroke: measurement, frequency, and recovery. Int Rehabil Med 1986; 8(2): 69-73, https://doi. org/10.3109/03790798609166178.

9. Wade D.T., Langton-Hewer R., Wood V.A., Skilbeck C.E., Ismail H.M. The hemiplegic arm after stroke: measurement and recovery. $J$ Neurol Neurosurg Psychiatry 1983; 46(6): 521-524, https://doi.org/10.1136/jnnp.46.6.521.

10. Bates B.E., Kwong P.L., Xie D., Valimahomed A., Ripley D.C., Kurichi J.E., Stineman M.G. Factors influencing receipt of early rehabilitation after stroke. Arch Phys Med Rehabil 2013; 94(12): 2349-2356, https://doi.org/10.1016/j. apmr.2013.07.021.

11. Bates B.E., Xie D., Kwong P.L., Kurichi J.E., Ripley D.C., Davenport C., Vogel W.B., Stineman M.G. 
Development and validation of prognostic indices for recovery of physical functioning following stroke: part 2. PM\&R 2015; 7(7): 699-710, https://doi.org/10.1016/j.pmrj.2015.01.012.

12. Bates B.E., Xie D., Kwong P.L., Kurichi J.E., Cowper Ripley D., Davenport C., Vogel W.B., Stineman M.G. Development and validation of prognostic indices for recovery of physical functioning following stroke: part 1. PM\&R 2015; 7(7): 685-698, https://doi.org/10.1016/j.pmrj.2015.01.011.

13. Arboix A. Stroke prognosis in diabetes mellitus: new insights but questions remain. Expert Rev Cardiovasc Ther 2009; 7(10): 1181-1185, https://doi.org/10.1586/erc.09.98.

14. Staub F., Bogousslavsky J. Post-stroke depression or fatigue? Eur Neurol 2001; 45(1): 3-5, https://doi. org/10.1159/000052081.

15. Chen Y.K., Qu J.F., Xiao W.M., Li W.Y., Weng H.Y., Li W., Liu Y.L., Luo G.P., Fang X.W., Ungvari G.S., Xiang Y.T. Poststroke fatigue: risk factors and its effect on functional status and health-related quality of life. Int J Stroke 2015; 10(4): 506-512, https://doi.org/10.1111/ijs.12409.

16. Naess H., Lunde L., Brogger J., Waje-Andreassen U. Fatigue among stroke patients on long-term follow-up. The Bergen Stroke Study. J Neurol Sci 2012; 312(1-2): 138-141, https://doi.org/10.1016/j.jns.2011.08.002.

17. Maaijwee N.A., Arntz R.M., Rutten-Jacobs L.C., Schaapsmeerders P., Schoonderwaldt H.C., van Dijk E.J., de Leeuw F.E. Post-stroke fatigue and its association with poor functional outcome after stroke in young adults. $J$ Neurol Neurosurg Psychiatry 2015; 86(10): 1120-1126, https://doi. org/10.1136/jnnp-2014-308784.

18. Suslina Z.A., Illarioshkin S.N., Piradov M.A. Neurology and neurosciences - prediction of development. Annaly klinicheskoy i eksperimental'noy nevrologii 2007; 1(1): 5-9.

19. The AVERT Trial Collaboration group. Efficacy and safety of very early mobilisation within $24 \mathrm{~h}$ of stroke onset (AVERT): a randomised controlled trial. Lancet 2015; 386(9988): 46-55, https://doi.org/10.1016/s01406736(15)60690-0.

20. Remple M.S., Bruneau R.M., VandenBerg P.M., Goertzen C., Kleim J.A. Sensitivity of cortical movement representations to motor experience: evidence that skill learning but not strength training induces cortical reorganization. Behav Brain Res 2001; 123(2): 133-141, https://doi.org/10.1016/s0166-4328(01)00199-1.

21. Luke L.M., Allred R.P., Jones T.A. Unilateral ischemic sensorimotor cortical damage induces contralesional synaptogenesis and enhances skilled reaching with the ipsilateral forelimb in adult male rats. Synapse 2004; 54(4): 187-199, https://doi.org/10.1002/syn.20080.

22. Reinkensmeyer D.J., Burdet E., Casadio M., Krakauer J.W., Kwakkel G., Lang C.E., Swinnen S.P., Ward N.S., Schweighofer N. Computational neurorehabilitation: modeling plasticity and learning to predict recovery. J Neuroeng Rehabil 2016; 13(1): 42, https://doi.org/10.1186/ s12984-016-0148-3.

23. Lang C.E., Lohse K.R., Birkenmeier R.L. Dose and timing in neurorehabilitation. Curr Opin Neurol 2015; 28(6): 549-555, https://doi.org/10.1097/wco.0000000000000256.

24. Lang C.E., Wagner J.M., Edwards D.F., Dromerick A.W. Upper extremity use in people with hemiparesis in the first few weeks after stroke. J Neurol Phys Ther 2007; 31(2): 56-63, https://doi.org/10.1097/npt.0b013e31806748bd.

25. Kumar P., Kathuria P., Nair P., Prasad K. Prediction of upper limb motor recovery after subacute ischemic stroke using diffusion tensor imaging: a systematic review and metaanalysis. J Stroke 2016; 18(1): 50-59, https://doi.org/10.5853/ jos.2015.01186.

26. Carr J.H., Shepherd R.B. Physiotherapy in disorders of the brain. Oxford: Butterworth Heinemann; 1980.

27. Carr J., Shepherd R. A motor relearningprogramme for stroke. London: William Heinemann Medical Books; 1982.

28. Horak F.B. Assumptions underlying motor control for neurologic rehabilitation. In: Foundation for physical therapy. Contemporary management of motor control problems. Proceedings of the II STEP conference. Alexandria, VA: Foundation for Physical Therapy; 1991; p. 11-27.

29. Woollacott M.H., Shumway-Cook A. Changes in posture control across the life span - a systems approach. Phys Ther 1990; 70(12): 799-807.

30. Chernikova L.A. Vosstanovitel'naya nevrologiya. Innovatsionnye tekhnologii $v$ neyroreabilitatsii [Restorative neurology. Innovative technologies in neurorehabilitation]. Moscow: Meditsinskoe informatsionnoe agentstvo; 2016; $344 \mathrm{p}$.

31. Usol'tseva E.V., Mashkara K.I. Khirurgiya zabolevaniy i povrezhdeniy kisti [Surgery of hand diseases and injuries]. Moscow: Meditsina; 1978; 336 p.

32. Kapandji A.I. The physiology of the joints: Vol. 1. Upper limb. Philadelphia, PA: Churchill Livingstone; 2007.

33. Santello M., Baud-Bovy G., Jörntell H. Neural bases of hand synergies. Front Comput Neurosci 2013; 7, https://doi. org/10.3389/fncom.2013.00023.

34. Chernikova L.A., Piradov M.A., Suponeva N.A., Chervyakov A.V., Klochkov A.S., Mokienko O.A., Lyukmanov R.Kh., Poydasheva A.G., Avdyunina I.A. Vysokotekhnologichnye metody neyroreabilitatsii pri zabolevaniyakh nervnoy sistemy. V kn.: Nevrologiya XXI veka: diagnosticheskie, lechebnye $i$ issledovatel'skie tekhnologii [Hi-tech methods of neurorehabilitation in nervous system diseases. In: Neurology of XXI century: diagnostic, therapeutic and research technologies]. Pod red. Piradova M.A., Illarioshkina S.N., Tanashyan M.M. [Piradov M.A., Illarioshkin S.N., Tanashyan M.M. (editors)]. Moscow; 2015; 274-331.

35. Veerbeek J.M., van Wegen E., van Peppen R., van der Wees P.J., Hendriks E., Rietberg M., Kwakkel G. What is the evidence for physical therapy poststroke? A systematic review and meta-analysis. PLoS One 2014; 9(2): e87987, https://doi. org/10.1371/journal.pone.0087987.

36. Waldner A., Tomelleri C., Hesse S. Transfer of scientific concepts to clinical practice: recent robot-assisted training studies. Funct Neurol 2009; 24(4): 173-177.

37. Hesse S., Schmidt H., Werner C., Bardeleben A. Upper and lower extremity robotic devices for rehabilitation and for studying motor control. Curr Opin Neurol 2003; 16(6): 705710, https://doi.org/10.1097/00019052-200312000-00010.

38. Balasubramanian S., Klein J., Burdet E. Robot-assisted rehabilitation of hand function. Curr Opin Neurol 2010; 23(6): 661-670, https://doi.org/10.1097/wco.0b013e32833e99a4.

39. Mehrholz J., Hädrich A., Platz T., Kugler J., Pohl M. Electromechanical and robot-assisted arm training for improving generic activities of daily living, arm function, and arm muscle strength after stroke. Cochrane Database Syst Rev 2012; 6: CD006876, https://doi.org/10.1002/14651858. cd006876.pub3.

40. Mehrholz J., Platz T., Kugler J., Pohl M. Electromechanical and robot-assisted arm training for 
improving arm function and activities of daily living after stroke. Cochrane Database Syst Rev 2008; 4: CD006876, https://doi. org/10.1002/14651858.cd006876.pub2.

41. Mehrholz J., Pohl M., Platz T., Kugler J., Elsner B. Electromechanical and robot-assisted arm training for improving activities of daily living, arm function, and arm muscle strength after stroke. Cochrane Database Syst Rev 2015; 11: CD006876, https://doi.org/10.1002/14651858. cd006876.pub4.

42. Aisen M.L. Krebs H.I., Hogan N., McDowell F., Volpe B.T. The effect of robot-assisted therapy and rehabilitative training on motor recovery following stroke. Arch Neurol 1997; 54(4): 443-446, https://doi.org/10.1001/ archneur.1997.00550160075019.

43. Volpe B.T., Krebs H.I., Hogan N., Edelsteinn L., Diels C.M., Aisen M.L. Robot training enhanced motor outcome in patients with stroke maintained over 3 years. Neurology 1999; 53(8): 1874-1874, https://doi.org/10.1212/ wnl.53.8.1874.

44. Fasoli S.E., Krebs H.I., Stein J., Frontera W.R., Hogan N. Effects of robotic therapy on motor impairment and recovery in chronic stroke. Arch Phys Med Rehabil 2003; 84(4): 477-482, https://doi.org/10.1053/apmr.2003.50110.

45. Fasoli S.E., Krebs H.I., Ferraro M., Hogan N., Volpe B.T. Does shorter rehabilitation limit potential recovery poststroke? Neurorehabil Neural Repair 2004; 18(2): 88-94, https://doi. org/10.1177/0888439004267434.

46. Krebs H.I., Volpe B.T., Williams D., Celestino J., Charles S.K., Lynch D., Hogan N. Robot-aided neurorehabilitation: a robot for wrist rehabilitation. IEEE Trans Neural Syst Rehabil Eng 2007; 15(3): 327-335, https://doi. org/10.1109/tnsre.2007.903899.

47. Masia L., Krebs H.I., Cappa P., Hogan N. Design and characterization of hand module for whole-arm rehabilitation following stroke. IEEE ASME Trans Mechatron 2007; 12(4): 399-340, https://doi.org/10.1109/tmech.2007.901928.

48. Lo A.C., Guarino P.D., Richards L.G., Haselkorn J.K., Wittenberg G.F., Federman D.G., Ringer R.J., Wagner T.H., Krebs H.I., Volpe B.T., Bever C.T. Jr., Bravata D.M., Duncan P.W., Corn B.H., Maffucci A.D., Nadeau S.E., Conroy S.S., Powell J.M., Huang G.D., Peduzzi P. Robotassisted therapy for long-term upper-limb impairment after stroke. N Engl J Med 2010; 362(19): 1772-1783, https://doi. org/10.1056/nejmoa0911341.

49. Lum P.S., Burgar C.G., Kenney D.E., Van der Loos H.F. Quantification of force abnormalities during passive and active-assisted upper-limb reaching movements in post-stroke hemiparesis. IEEE Trans Biomed Eng 1999; 46(6): 652-662, https://doi.org/10.1109/10.764942.

50. Lum P.S., Burgar C.G., Shor P.C. Evidence for improved muscle activation patterns after retraining of reaching movements with the MIME robotic system in subjects with poststroke hemiparesis. IEEE Trans Neural Syst Rehabil Eng 2004; 12(2): 186-194, https://doi.org/10.1109/tnsre.2004.827225.

51. Lum P.S., Burgar C.G., Van der Loos M., Shor P.C., Majmundar M., Yap R. MIME robotic device for upper-limb neurorehabilitation in subacute stroke subjects: a follow-up study. J Rehabil Res Dev 2006; 43(5): 631-632, https://doi. org/10.1682/jrrd.2005.02.0044.

52. Burgar C.G., Lum P.S., Scremin A.M., Garber S.L., Van der Loos H.F., Kenney D., Shor P. Robot-assisted upperlimb therapy in acute rehabilitation setting following stroke: Department of Veterans Affairs multisite clinical trial. J Rehabil
Res Dev 2011; 48(4): 445-458, https://doi.org/10.1682/ jrrd.2010.04.0062.

53. Hesse S., Schulte-Tigges G., Konrad M., Bardeleben A., Werner C. Robot-assisted arm trainer for the passive and active practice of bilateral forearm and wrist movements in hemiparetic subjects. Arch Phys Med Rehabil 2003; 84(6): 915-920, https://doi.org/10.1016/s0003-9993(02)04954-7.

54. Hesse S., Werner C., Pohl M., Rueckriem S., Mehrholz J., Lingnau M.L. Computerized arm training improves the motor control of the severely affected arm after stroke: a single-blinded randomized trial in two centers. Stroke 2005; 36(9): 1960-1966, https://doi.org/10.1161/01. str.0000177865.37334.ce.

55. Liao W.W., Wu C.Y., Hsieh Y.W., Lin K.C., Chang W.Y. Effects of robot-assisted upper limb rehabilitation on daily function and real-world arm activity in patients with chronic stroke: a randomized controlled trial. Clin Rehabil 2012; 26(2): 111-120, https://doi.org/10.1177/0269215511416383.

56. Yang C.L., Lin K.C., Chen H.C., Wu C.Y., Chen C.L. Pilot comparative study of unilateral and bilateral robotassisted training on upper-extremity performance in patients with stroke. Am J Occup Ther 2012; 66(2): 198-206, https:// doi.org/10.5014/ajot.2012.003103.

57. Picelli A., Tamburin S., Passuello M., Waldner A., Smania N. Robot-assisted arm training in patients with Parkinson's disease: a pilot study. J Neuroeng Rehabil 2014; 11: 28, https://doi.org/10.1186/1743-0003-11-28.

58. Masiero S., Celia A., Armani M., Rosati G., Tavolato B., Ferraro C., Ortolani M. Robot-aided intensive training in poststroke recovery. Aging Clin Exp Res 2006; 18(3): 261-265, https://doi.org/10.1007/bf03324658.

59. Masiero S., Celia A., Armani M., Rosati G. A novel robot device in rehabilitation of post-stroke hemiplegic upper limbs. Aging Clin Exp Res 2006; 18(6): 531-535, https://doi. org/10.1007/bf03324854.

60. Masiero S., Celia A., Rosati G., Armani M. Roboticassisted rehabilitation of the upper limb after acute stroke. Arch Phys Med Rehabil 2007; 88(2): 142-149, https://doi. org/10.1016/j.apmr.2006.10.032.

61. Masiero S., Armani M., Rosati G. Upper-limb robotassisted therapy in rehabilitation of acute stroke patients: focused review and results of new randomized controlled trial. J Rehabil Res Dev 2011; 48(4): 355-366, https://doi. org/10.1682/jrrd.2010.04.0063.

62. Masiero S., Armani M., Ferlini G., Rosati G., Rossi A. Randomized trial of a robotic assistive device for the upper extremity during early inpatient stroke rehabilitation. Neurorehabil Neural Repair 2014; 28(4): 377-386, https://doi. org/10.1177/1545968313513073.

63. Bastiaens H., Alders G., Feys P., Notelaers S., Coninx K., Kerkhofs L., Truyens V., Geers R., Goedhart A. Facilitating robot-assisted training in MS patients with arm paresis: a procedure to individually determine gravity compensation. IEEE Int Conf Rehabil Robot 2011; 2011: 5975507, https://doi.org/10.1109/icorr.2011.5975507.

64. Huang V.S., Krakauer J.W. Robotic neurorehabilitation: a computational motor learning perspective. J Neuroeng Rehabil 2009; 6: 5, https://doi.org/10.1186/1743-0003-6-5.

65. Kwakkel G., Kollen B.J., Krebs H.I. Effects of robotassisted therapy on upper limb recovery after stroke: a systematic review. Neurorehabil Neural Repair 2008; 22(2): 111-121, https://doi.org/10.1177/1545968307305457.

66. Norouzi-Gheidari N., Archambault P.S., Fung J. 
Effects of robot-assisted therapy on stroke rehabilitation in upper limbs: systematic review and meta-analysis of the literature. J Rehabil Res Dev 2012; 49(4): 479-496, https://doi. org/10.1682/jrrd.2010.10.0210.

67. Hu X.L., Tong K.Y., Song R., Zheng X.J., Lui K.H., Leung W.W., Ng S., Au-Yeung S.S. Quantitative evaluation of motor functional recovery process in chronic stroke patients during robot-assisted wrist training. J Electromyogr Kinesiol 2009; 19(4): 639-650, https://doi.org/10.1016/j. jelekin.2008.04.002.

68. Prange G.B., Jannink M.J.A., GroothuisOudshoorn C.G.M., Hermens H.J., IJzerman M.J. Systematic review of the effect of robot-aided therapy on recovery of the hemiparetic arm after stroke. J Rehabil Res Dev 2006; 43(2): 171-184, https://doi.org/10.1682/jrrd.2005.04.0076.

69. Stein J., Krebs H.I., Frontera W.R., Fasoli S.E., Hughes R., Hogan N. Comparison of two techniques of robotaided upper limb exercise training after stroke. Am J Phys Med Rehabil 2004; 83(9): 720-728, https://doi.org/10.1097/01. phm.0000137313.14480.ce.

70. Riener R., Nef T., Colombo G. Robot-aided neurorehabilitation of the upper extremities. Med Biol Eng Comput 2005; 43(1): 2-10, https://doi.org/10.1007/bf02345116.

71. Nef T., Guidali M., Riener R. ARMin III - arm therapy exoskeleton with an ergonomic shoulder actuation. Appl Bionics Biomech 2009; 6(2): 127-142, https://doi. org/10.1080/11762320902840179.

72. Howlett O.A., Lannin N.A., Ada L., McKinstry C. Functional electrical stimulation improves activity after stroke: a systematic review with meta-analysis. Arch Phys Med Rehabil 2015; 96(5): 934-943, https://doi.org/10.1016/j. apmr.2015.01.013.

73. Alon G., Conroy V.M., Donner T.W. Intensive training of subjects with chronic hemiparesis on a motorized cycle combined with functional electrical stimulation (FES): a feasibility and safety study. Physiother Res Int 2010; 16(2): 81-91, https://doi.org/10.1002/pri.475.

74. Hu X.L., Tong K.Y., Li R., Xue J.J., Ho S.K., Chen P. The effects of electromechanical wrist robot assistive system with neuromuscular electrical stimulation for stroke rehabilitation. J Electromyogr Kinesiol 2012; 22(3): 431-439, https://doi. org/10.1016/j.jelekin.2011.12.010.

75. Li Z., Wang B., Sun F., Yang C., Xie Q., Zhang W. sEMG-based joint force control for an upper-limb power-assist exoskeleton robot. IEEE J Biomed Health Inform 2014; 18(3): 1043-1050, https://doi.org/10.1109/jbhi.2013.2286455.

76. Cesqui B., Mezzetti M., Lacquaniti F., d'Avella A. Gaze behavior in one-handed catching and its relation with interceptive performance: what the eyes can't tell. PLoS One 2015; 10(3): e0119445, https://doi.org/10.1371/journal.pone.0119445.

77. Rong W., Tong K.Y., Hu X.L., Ho S.K. Effects of electromyography-driven robot-aided hand training with neuromuscular electrical stimulation on hand control performance after chronic stroke. Disabil Rehabil Assist Technol 2013; 10(2): 149-159, https://doi.org/10.3109/174831 07.2013.873491.

78. Song R., Tong K., Hu X., Zhou W. Myoelectrically controlled wrist robot for stroke rehabilitation. $J$ Neuroeng Rehabil 2013; 10(1): 52, https://doi.org/10.1186/1743-0003-10-52.

79. Belardinelli A., Stepper M.Y., Butz M.V. It's in the eyes: planning precise manual actions before execution. $J$ Vis 2016; 16(1): 18, https://doi.org/10.1167/16.1.18.

80. Schnorenberg A.J., Campbell-Kyureghyan N.H.,
Beschorner K.E. Biomechanical response to ladder slipping events: effects of hand placement. J Biomech 2015; 48(14): 3810-3815, https://doi.org/10.1016/j.jbiomech.2015.09.001.

81. Bozzacchi C., Domini F. Lack of depth constancy for grasping movements in both virtual and real environments. J Neurophysiol 2015; 114(4): 2242-2248, https://doi. org/10.1152/jn.00350.2015.

82. Chernikova L.A. Novel technologies in rehabilitation of stroke patients. Atmosfera. Nervnye bolezni 2005; 2: 32-35.

83. Schabowsky C.N., Godfrey S.B., Holley R.J., Lum P.S. Development and pilot testing of HEXORR: hand EXOskeleton rehabilitation robot. J Neuroeng Rehabil 2010; 7(1): 36, https:// doi.org/10.1186/1743-0003-7-36.

84. Brokaw E.B., Black I., Holley R.J., Lum P.S. Hand Spring Operated Movement Enhancer (HandSOME): a portable, passive hand exoskeleton for stroke rehabilitation. IEEE Trans Neural Syst Rehabil Eng 2011; 19(4): 391-399, https://doi.org/10.1109/tnsre.2011.2157705.

85. Feigin V.L., Forouzanfar M.H., Krishnamurthi R., Mensah G.A., Connor M., Bennett D.A., Moran A.E., Sacco R.L., Anderson L., Truelsen T., O'Donnell M., Venketasubramanian N., Barker-Collo S., Lawes C.M., Wang W., Shinohara Y., Witt E., Ezzati M., Naghavi M., Murray C. Global and regional burden of stroke during 19902010: findings from the Global Burden of Disease Study 2010. Lancet 2014; 383(9913): 245-255, https://doi.org/10.1016/ s0140-6736(13)61953-4.

86. Ates S., Lobo-Prat J., Lammertse P., van der Kooij H., Stienen A.H.A. SCRIPT passive orthosis: design and technical evaluation of the wrist and hand orthosis for rehabilitation training at home. IEEE Int Conf Rehabil Robot 2013; 2013: 6650401, https://doi.org/10.1109/icorr.2013.6650401.

87. Vanoglio F., Luisa A., Garofali F., Mora C. Evaluation of the effectiveness of Gloreha (Hand Rehabilitation Glove) on hemiplegic patients. Pilot study. In: XIII Congress of Italian Society of Neurorehabilitation, 18-20 April 2013, Bari (Italy).

88. Ho N.S., Tong K.Y., Hu X.L., Fung K.L., Wei X.J., Rong W., Susanto E.A. An EMG-driven exoskeleton hand robotic training device on chronic stroke subjects: task training system for stroke rehabilitation. IEEE Int Conf Rehabil Robot 2011; 2011: 5975340, https://doi.org/10.1109/ icorr.2011.5975340.

89. Lambercy O., Schröder D., Zwicker S., Gassert R. Design of a thumb exoskeleton for hand rehabilitation. In: Proceedings of the $7^{\text {th }}$ International Convention on Rehabilitation Engineering and Assistive Technology. Singapore; 2013; p. 41.

90. Stein J., Bishop L., Gillen G., Helbok R. A pilot study of robotic-assisted exercise for hand weakness after stroke. IEEE Int Conf Rehabil Robot 2011; 2011: 5975426, https://doi. org/10.1109/icorr.2011.5975426.

91. Lambercy O., Robles A.J., Kim Y., Gassert R. Design of a robotic device for assessment and rehabilitation of hand sensory function. IEEE Int Conf Rehabil Robot 2011; 2011: 5975436, https://doi.org/10.1109/icorr.2011.5975436.

92. Topping M. An overview of the development of Handy 1 , a rehabilitation robot to assist the severely disabled. Artificial Life and Robotics 2000; 4(4): 188-192, https://doi.org/10.1007/ bf02481173.

93. Mokienko O.A., Chervyakov A.V., Kulikova S.N., Bobrov P.D., Chernikova L.A., Frolov A.A., Piradov M.A. Increased motor cortex excitability during motor imagery in brain-computer interface trained subjects. Front Comput 
Neurosci. 2013; 7: 168, https://doi.org/10.3389/fncom.2013. 00168.

94. Soekadar S.R., Silvoni S., Cohen L.G., Birbaumer N. Brain-machine interfaces in stroke neurorehabilitation. Clinical Systems Neuroscience 2014; 3-14, https://doi. org/10.1007/978-4-431-55037-2_1.

95. Ang K.K., Chua K.S., Phua K.S., Wang C., Chin Z.Y., Kuah C.W., Low W., Guan C. A randomized controlled trial of EEG-based motor imagery brain-computer interface robotic rehabilitation for stroke. Clin EEG Neurosci 2014; 46(4): 310320, https://doi.org/10.1177/1550059414522229.

96. Mokienko O.A., Lyukmanov R.Kh., Chernikova L.A., Suponeva N.A., Piradov M.A., Frolov A.A. Brain-computer interface: the first clinical experience in Russia. Fiziologiya cheloveka 2016; 42(1): 31-39, https://doi.org/10.7868/ s0131164616010136.

97. Frolov A.A., Mokienko O., Lyukmanov R.Kh., Chernikova L.A., Kotov S.V., Turbina L.G., Bobrov P.D., Biryukova E.V., Kondur A.A., Ivanova G.E., Staritsyn A.N., Bushkova Yu.V., Dzhalagoniya I.Z., Kurganskaya M.E., Pavlova O.G., Budilin S.Yu., Aziatskaya G.A., Khizhnikova A.E., Chervyakov A.V., Lukyanov A.L., Nadareyshvily G.G. Preliminary results of a controlled study of $\mathrm{BCl}$-exoskeleton technology efficacy in patients with poststroke arm paresis. Vestnik Rossiyskogo gosudarstvennogo meditsinskogo universiteta 2016; 2: 17-25. 